\title{
Particulate Matter in Injectables: Main cause for Recalls
}

\section{Suprita A Tawde}

Akorn Pharmaceuticals Inc, USA

*Corresponding author: Suprita A Tawde, Akorn Pharmaceuticals Inc, USA, Tel: 847-990-1721; E-mail: suprita.tawde@akorn.com

Rec date: Dec 26, 2014; Acc date: Dec 29, 2014; Pub date: Jan 05, 2015

Copyright: () 2014 Tawde SA. This is an open-access article distributed under the terms of the Creative Commons Attribution License, which permits unrestricted use, distribution, and reproduction in any medium, provided the original author and source are credited.

\section{Editorial}

Presence of foreign visible or sub-visible particulate matter in injectable/ parenteral formulations has been one of the most commonly seen reasons for recalls. FDA reported $22 \%$ recalls for sterile injectable drugs in period of 2008-2012 caused due to presence of visible particles [1]. Recent 2014 list of FDA recalls include the products as mentioned in the Table 1 [2]. All injectables are mostly contaminated with some level of particulate matter. This Particulate matter is a critical quality attribute which has direct impact on product

\begin{tabular}{|c|c|c|}
\hline Product & Manufacturer & Reason \\
\hline IV Sodium Chloride and Potassium Chloride Solutions & Baxter & $\begin{array}{l}\text { Particulate Matter } \\
\text { (cellulosic fibers and/or plastics) }\end{array}$ \\
\hline CLINIMIX and CLINIMIX E Injection & Baxter & Particulate Matter \\
\hline CUBICIN (daptomycin for injection) & $\begin{array}{l}\text { Cubist } \\
\text { Pharmaceuticals }\end{array}$ & Particulate Matter (glass particles) \\
\hline $\begin{array}{l}\text { Dianeal Low Calcium }(2.5 \mathrm{mEq} / \mathrm{L}) \text { Peritoneal Dialysis Solution } \\
\text { with } 2.5 \text { Percent Dextrose } 5000 \mathrm{~mL} \text { (Ambu-Flex II) }\end{array}$ & Baxter & $\begin{array}{l}\text { Particulate Matter } \\
\text { (presence of oxidized stainless steel, garment fiber, and PVC } \\
\text { particulate matter) }\end{array}$ \\
\hline Coumadin (warfarin sodium) for Injection & Bristol-Myers Squibb & Particulate Matter (metallic and non-metallic cellulose materia) \\
\hline Dobutamine Injection $(250 \mathrm{mg} / 20 \mathrm{~mL})$ & Hospira & Visible Particulates \\
\hline $\begin{array}{l}\text { Heparin Sodium, 1,000 USP Heparin Units } / 500 \mathrm{~mL}(2 \text { USP } \\
\text { Heparin Units } / \mathrm{mL}), \text { In } 0.9 \text { percent Sodium Chloride Injection, } 500 \\
\mathrm{~mL}\end{array}$ & Hospira & Particulate Matter (human hair) \\
\hline $\begin{array}{l}\text { Lidocaine } \mathrm{HCl} \text { Injection, USP } 10 \mathrm{MG} \text { Per ML, } 30 \mathrm{ML} \text { Single- } \\
\text { Dose, Preservative-Free }\end{array}$ & Hospira & Particulate Matter (human hair) \\
\hline Lidocaine $\mathrm{HCl}$ Injection, USP, 2 percent & Hospira & Visible Particulates (iron oxide) \\
\hline $\begin{array}{l}\text { Marcaine (Bupivacaine } \mathrm{HCl} \text { Injection, USP), } 0.5 \text { percent, } 30 \mathrm{ML} \text {, } \\
\text { Single-Dose, Preservative-Free Vial }\end{array}$ & Hospira & Visible Particulates (glass defect) \\
\hline $\begin{array}{l}\text { Marcaine (Bupivacaine } \mathrm{HCl} \text { Injection, USP) } 0.25 \text { percent, } 10 \mathrm{ml} \text {, } \\
\text { Single-Dose, Preservative-Free Vial }\end{array}$ & Hospira & Visible Particulates (glass defect) \\
\hline Propofol Injectable Emulsion, USP & Hospira & Visible Particulates (glass defect) \\
\hline $\begin{array}{l}\text { 0.9 Percent Sodium Chloride Injection USP in } 100 \mathrm{~mL} \text { MINI-BAG } \\
\text { PLUS Container }\end{array}$ & Baxter & Particulate Matter \\
\hline Soliris (eculizumab) Concentrated Solution for IV Infusion & Alexion & Visible Particulates \\
\hline VPRIV (velaglucerase alfa for injection) & Shire Pharmaceuticals & Particulate Matter (stainless steel and barium sulfate) \\
\hline $\begin{array}{l}\text { Labetalol Hydrochloride Injection } 100 \text { MG/20 ML (5MG/ML), } 20 \\
\text { ML, Multidose Vial }\end{array}$ & Hospira & Visible Particulates (stainless steel and iron oxide) \\
\hline
\end{tabular}

Table 1: List of Recalls reported by FDA in 2014. standards for particulate matter. These standards are established for all injectable preparations such as large-volume Injections for single-dose infusion and small-volume Injections, solutions for injection administered by intramuscular or subcutaneous route, except parenterals for use as irrigating solutions, radiopharmaceutical preparations and parenteral products for which the labeling specifies use of a final filter prior to administration $[3,4]$. 
Page 2 of 2

As per these standards, each final container of all parenteral preparations needs be inspected for the presence of observable foreign and particulate matter (visible particulates) in its contents. Inspection conditions defined by USP $<790>$ details the use of 2,000-3,750 lux lamp, inspection against black and white backgrounds, with no magnification and $5 \mathrm{sec}$ viewing against each background, swirl and/or invert sample [5]. Every container whose contents show evidence of visible particulates has to be rejected. Thus, all injectables need to be essentially free of foreign particles. However, visual inspection cannot detect smaller particles precisely as the visibility of the naked human eye is limited to approximately $40 \mu \mathrm{m}$ [6]. Therefore, for sub-visible particulate matter, two methods are specified by USP such as Light Obscuration Particle Count Test and Microscopic Particle Count Test to be performed on the representative samples of each lot. In the most of injectables, Light Obscuration Method is preferred. However, when this method is not applicable, e.g., in the case of preparations such as Emulsions, colloids, and liposomal preparations with reduced clarity or high viscosity or for preparation which generate air or gas bubbles limiting the use of Light Obscuration Particle Count Test, Microscopic Particle Count Test is used [3]. The Light Obscuration Particle Count Test is based on the principle of light blockage that allows an automatic determination of the size of particles and the number of particles according to size. As per this method, for large volume injectables more than $100 \mathrm{~mL}$, the preparation complies with the test if the average number of particles does not exceed 25 per $\mathrm{mL}$ equal to or greater than $10 \mu \mathrm{m}$ and does not exceed 3 per $\mathrm{mL}$ equal to or greater than $25 \mu \mathrm{m}$. While for small volume injectables less than $100 \mathrm{~mL}$, the preparation complies with the test if the average number of particles does not exceed 6000 per container equal to or greater than $10 \mu \mathrm{m}$ and does not exceed 600 per container equal to or greater than $25 \mu \mathrm{m}[3,6]$. The microscopic particle count test involves filtering the sample through a microporous membrane filter and counting the particles collected on the membrane under a compound binocular microscope. As per Microscopic Particle Count Test, for large volume injectables, the preparation complies with the test if the average number of particles present in the units tested does not exceed 12 per $\mathrm{mL}$ equal to or greater than $10 \mu \mathrm{m}$ and does not exceed 2 per $\mathrm{mL}$ equal to or greater than $25 \mu \mathrm{m}$. While, for small volume injectables, the preparation complies with the test if the average number of particles present in the units tested does not exceed 3000 per container equal to or greater than $10 \mu \mathrm{m}$ and does not exceed 300 per container equal to or greater than $25 \mu \mathrm{m}[3,6]$.

The presence of particulate matter in larger numbers can pose lifethreatening health hazards. These particles are foreign /extraneous mobile undissolved particles, other than gas bubbles, unintentionally present in the solutions. There can be various sources of such particles such as environmental factors (fibers, dust, personnel), packaging components (rubber closures, glass vials, silica, plastic, polymers, silicone, latex), formulation (agglomerates, precipitates, undissolved material, drug/ excipient incompatibility issues) or manufacturing process related factors (metal, filters) etc. [7]. Recently glass delamination has been cited as a reason for recall which is caused by the formation of glass lamellae over the product shelf life [8]. This Particulate matter can result in severe consequences, such as vein irritation, anaphylactic shock, phlebitis, pulmonary emboli, pulmonary granulomas, immune system dysfunction, pulmonary dysfunction, infarction, and death, based upon the number of particles, particle size/ shape, patient population, particle composition and route of administration. The size of particulate matter is an important factor behind health risk to patients. The smallest diameter of blood capillaries is approximately $6-8 \mu \mathrm{m}$. Particles as small as $2 \mu \mathrm{m}$ in diameter are generally associated with micro-thrombi formation in patients. Particles larger than 6-8 um can block pulmonary capillaries, with smaller particles passing through the lungs and depositing in organs such as the liver and spleen, where they are processed by phagocytic cells of the reticuloendothelial system [6,7]. There are several measures which are currently being followed for preventing the presence of particulate matter beyond the acceptable levels in the formulation such as clean room design and operation, aseptic techniques (isolators), vial/stopper washing equipment design and operation, gown and wipes selection, use of sterile filtration with 0.22 $\mu \mathrm{m}$ filters (in-line during filling, at the point of use), inspection of parenteral preparations for the presence of visible as well as sub-visible foreign particulate matter and rejection of container with visible particulates or with sub visible particles beyond acceptable limits by USP. The human inspection needs to consider visual acuity, and fatigue. In case of dry-heat sterilization process, the contents need to be passed through at least a $5-\mu \mathrm{m}$ filter prior to dry-heat sterilizing in the final container. In addition, close observation of contents of injectable preparations is followed throughout shelf life to ensure safety of patients $[1,6]$.

In conclusion, the extent of foreign particulate matter present in injectables indicates the pharmaceutical quality of the product. Therefore, it requires continued efforts to minimize as well to monitor the particles in the product by following all possible measures.

\section{References}

1. Shabushnig JG (2014) Detection and Control of Visible Particles in injectable products.

2. Safety Alerts for Human Medical Products (2014).

3. United States Pharmacopoeia chapter 788, Particulate Matter in Injections.

4. United States Pharmacopoeia chapter 1, injections.

5. United States Pharmacopoeia, chapter 790, Visible Particulates in Injections.

6. Tran T, Kupiec T, Trissel L (2006) Quality Control Analytical Methods: Particulate Matter in Injections: What is it and what are the concerns? International Journal of Pharmaceutical Compounding 10: 202-204.

7. Langille S (2006) Particulate Matter in Injectable Drug Products. PDA Journal of Pharmaceutical Science and Technology 67: 186-200.

8. United States Pharmacopoeia chapter 1660, Evaluation of the Inner Surface Durability of Glass Containers. 